\title{
Analysis on the Effective Integration of Information Technology and Personnel Management in Colleges and Universities
}

\author{
Yong Liu \\ Personnel Department, China West Normal University, Nanchong, China \\ Email: guicaitang@163.com
}

Received 15 April 2015; accepted 18 May 2015; published 21 May 2015

Copyright (C) 2015 by author and Scientific Research Publishing Inc.

This work is licensed under the Creative Commons Attribution International License (CC BY).

http://creativecommons.org/licenses/by/4.0/

c) (i) Open Access

\begin{abstract}
Along with the continuous economic and social development and the unceasing progress of science and technology, information technology has penetrated into every field of social life. Therefore, colleges and universities face with serious challenges in personnel management. This needs the continuous integration of information technology and the personnel management in colleges and universities to ensure the working efficiency. This paper first analyses the meaning of integration of information technology and the personnel management in colleges and universities, and then states the present situation of the personnel management information in colleges and universities, analyses the measures of the effective integration of information technology and the personnel management in colleges and universities.
\end{abstract}

\section{Keywords}

Information Technology, Personnel Management Information in Colleges and Universities, Importance, Present Situation, Countermeasure

\section{Introduction}

In the $21^{\text {st }}$ century, China social development is in rapid information development. The digitization and intellectualization of the information technology have very important function on the development of teaching resources and the optimizing of teaching processes, as well as on the improvement of students' comprehensive quality. The application of information technology has changed the traditional management mode of higher education, realizing the continuous improvement in working efficiency. The system reform of colleges and universities adds the specialty and complexity of personnel management. Therefore, many factors including large 
amounts of information, frequent changes of information and policy restrain, etc. made the personnel management in colleges and universities faced with severe challenges. This needs the information construction of personnel management to provide important safeguard to the carrying out of personnel management in colleges and universities smoothly (Luo, 2008).

\section{The Meaning of the Integration of Information Technology and the Personnel Management in Colleges and Universities}

Along with the deepening of education system reform and the development of the educational cause, the personnel management in colleges and universities is becoming more and more important gradually, and develops into the fundamental basis and safeguard to the smooth carrying out of other work. The personnel management in the higher education mainly refers to that under the limitation of certain personnel policies and relative principles, the personnel management staff carry out the management on the behavioral patterns and norms of certain groups of people in the universities through the operation and adjustment of personnel system, the coordination and integration of human relations, and the participation and processing of specific affairs in universities, etc. (Bing, 2012). In fact, the personnel management in colleges and universities covers an extensive working scope, has a large amount of actual information capacity and relatively disorderly management contents. In addition, it requires high on the effectiveness and the relevance of information, and also requires strictly on the consistency of various information.

With the development of information society, the personnel management in colleges and universities takes more emphasis on the informedness. The staff of personnel management should constantly make collection and classification, archive and storage, statistics and analysis on the data, however, the degree of informatization still under great restrictions. With the coming of the internet era, the personnel management in colleges and universities should undergo fundamental and structural changes, so as to meet their practical developing demands. The personnel management in colleges and universities should change the tradition situation of passive management into active providing of human resources development and human resources services, so as to realize the more efficient scientific research and teaching service, achieve the construction of harmonious development environment and the full development of the universities' causes. The integration of information technology and the personnel management in colleges and universities is imperative (Wang, 2011).

\section{Integration Status of Information Technology and the Personnel Management in Colleges and Universities}

From the development in recent years, the information construction in colleges and universities has achieved great results. The construction of the campus network infrastructures, the construction of information system and the development of information resources, and the cultivation of information professionals have all made significant achievements.

\subsection{The Lack of a Correct Understanding on the Integration of Information Technology and the Personnel Management in Colleges and Universities}

In the integration process of information technology and the personnel management in colleges and universities, the establishment of the information management concept and the strengthening of the information-based consciousness have very importance function on its development. The integration of information technology and the personnel management in colleges and universities relates to the whole process of personnel management. However, some people haven't been fully aware of the importance and function of the integration. Their management concepts are outdated, which still employ the traditional method to make the construction and management of information in actual work. Some people even thought that the integration is only the application of a few machine and a self create personnel management system, and thus ignored the processes of reprocessing and construction. These resulted to the passive and lagging situation of the overall integration work.

\subsection{Irrationality of the Development of the Personnel Information Management System}

Related departments tend to offer facilities and statistics for the storage and search of the data, which made the actual personnel management process being lack of the systematic analysis. The unclear division of the related 
job functions resulted to the uncertainty of the actual work distributions. The development team of the personnel management system was limited by several factors like the limitation of cognition and not enough communication, insufficient support of the actual development fees, and so on, which made the function of the whole software too easy and cannot meet the requirements of find information and processing (Zhang, 2014). In addition, in the operating process of the one machine system, the formation of a certain application cannot be integrated, resulted to the hindering of data sharing. Therefore, there are repeatability and redundancy on different systems, and the lacking of the data publishing function lead to the fact that the effective information cannot be used normally.

\subsection{Deficiency of the Information Dealing Ability of the Personnel Management Staff}

As the direct beneficiary of information management and construction, the staff should recognize the important function they played in the management process. The level of their qualities and abilities has very important influence on the management level and the construction of information. In the actual work, some staff only know the maintenance of the data base, for example, add, modify and delete of information, the search and statistics of information data, and so on. They neither have the academic mastery of multi-dimensional analysis of the data and the analysis report writing ability, nor the ability of digging deep and effective information, thus hindered the generalizing of scientific decision. In addition, in the information management process, there is no excavation of the deeper function, and the gap between the statistics of data and the mastery of the information recognition existed, made the information management lace the actual conditions.

\section{Countermeasure Analysis on the Effective Integration of Information Technology and the Personnel Management in Colleges and Universities}

Before you begin to format your paper, first write and save the content as a separate text file. Keep your text and graphic files separate until after the text has been formatted and styled. Do not use hard tabs, and limit use of hard returns to only one return at the end of a paragraph. Do not add any kind of pagination anywhere in the paper. Do not number text heads - the template will do that for you.

\subsection{Taking the Objective Information as the Fundamental Basis to Realize the Establishment of Correct Value Orientation}

In the integration process of information technology and the personnel management in colleges and universities, justice is a concept and category related to fair and equity, which essence is the representation of justice. In the integration process, justice means that the informative system has important function to the future development and the rationality and urgency of the actual implement. In the meantime, justice also is the essential safeguard of the necessity of proposing informative management mode. This will help to give consideration to value and technology in the same time and realize the balance and unity with instrumental function as well (Yao, 2012). In the integration process of information technology and the personnel management in colleges and universities, the objective information should be the important developing basis, providing safeguard to the justice of the management process. Due to the set convenience of the information flowing channel, normalization and orderliness should be abided by in the actual work. The information process is the smoothing process of administrative process, which order is realized by the justice of process. The integration of management also provides important guarantee to the administrative discretional right. Therefore, in the process of actual management, one should make judgment and decision according to the existing situation. Through the balancing of the interests of different parts to realize the completion of effective information, and thus provide guarantee to the implementation and improving of the administrative discretional right.

\subsection{Realize the Establishment of Informative Management System by the Campus Network Platform}

Due to the large randomness in the personnel management in colleges and universities, and the heavy workload of the statistics and query of the relevant information of the teaching and administrative staff and the urgent requirement of the work, the repetitive work has great influences on the work efficiency and the working enthusiasm. With the help of campus network resources, and take it as an important platform, colleges and universi- 
ties can establish the relational database management system to achieve the strengthening of its functionality. At the same time, the personnel management work system with strong practicability will ensure the constant improvement of the working efficiency. In the construction of information management system, the building and perfection of the basic personnel information could be realized. On the base of the raw data accumulation of the campus personnel archives, there should be professional staff to do the data collection and in-put of information data, as well as the in time update of the main information. The classification and storage of the information data could also be realized through the approval of the personnel department, which will make the working efficiency of personnel management be improved gradually. The problems of irrational structure and the redundancy of the data could be dealt through the application of information technology, realizing the classification and induction of the personnel information through the continuous standardization of the database, and finally achieving the standardized management of the data. The personnel information management system could be established through the setting up of the network office work model, and thus will free the related personnel working staff of colleges and universities from the information collection and the data input. The construction of the management of teacher resource data platform and the planning of the teaching staff will provide referential scientific basis for the teacher.

\subsection{The Construction of Information Management Group through Information Technology}

The improvement of the personnel information management efficiency should rely on the research and development of the personnel management system and the continuous development strategy, as well as a reserve team of information technology professionals. In the integration of information technology and the personnel management in colleges and universities, there should be very strict requirements on the comprehensive qualities of the personnel management staff, who not only obtain the fine ideological and ethical qualities, but also master the modern teaching concept, realizing the constant improvement of education management approaches and methods by the mastery of computer related professional knowledge (Li, 2000). Through the improvement of the application ability of the personnel management staff, their abilities on information processing and obtaining will be improved too, and thus the actual requirement of the information development of the colleges and universities' personnel management will be satisfied. In the process of integration, several measures should be applied to ensure the planned training of the related personnel staff on the information knowledge and skills. The related staff should change their traditional cognition concept, providing more professional services for the human resources work through the establishment of the people-oriented concept, and strengthen the reform of the related work, finally achieve the skilled grasping of the related policies and regulations on personnel management. Through the establishing and perfecting of the working system related to information collection and publishing, the standardization and the rapidness of the work could be ensured, and the improvement of personnel management efficiency could be realized (Liu, 2008). The related staffs on personnel management need to improve their consciousness on self-study, accumulating more related knowledge by the raising of personal comprehensive quality, mastering the modern information technology through the renew and widening of their skills, and improving the adaptability toward own work.

\subsection{Realize the Formation of Effective Development through the Establishment of Information Sharing Object}

With the continuous social development and the fastening of information construction, the construction of personnel information process in colleges and universities set strict requirements on the informationization of the personnel department, which requires the strengthening of the overall viewpoint to realize the building of information sharing consciousness. In the personnel management in colleges and universities, in addition to the work of the personnel department, they should exchange information with other related functional departments, thus to process the overlapping information. In the management process of personnel information, the related staff should fully employ the online resources of the universities and the multimedia technology to maintain the information sharing and communication among different departments, realizing the unification and standardization of personnel management and providing more effective and safer management channel for them at last (Ma, 2007). Through the integration, a system that can realize the effectiveness of codetermination could be built, which could realize the integration and complementation to the contents through the using of non-confrontation 
among objects, and maintain the harmony of recognition relations and the smoothness of information by the equal coordination relationship. At last, it can maintain the working efficiency and cohesive force of the staff and better play their working enthusiasm.

\section{Conclusion}

The management and implementation of the decision have very important influence on the personnel management process in colleges and universities, which also need the integration of macro and micro management to realize the combination of system and information. Through the integration of information technology and personnel management in colleges and universities to realize the improving of work efficiency, as well as the achievement of work, the joint force will be formed, and superior and high-effective management and service for the further development of the colleges and universities will be provided.

\section{References}

Bing, Y. (2012). Analysis on the Curriculum Standards of Junior High School Physics. Education Science \& Culture Magazine, No. 4, 110-111.

Li, H. J. (2000). Construction of Personnel Management in Colleges and Universities. Journal of Nanjing University of Aeronautics and Astronautics, No. 3, 65-67.

Liu, Z. G. (2008) Understanding and Thinking on the Construction of Campus Informationization. Journal of Shanxi Finance and Tax College, No. 1, 79-80.

Luo, L. X. (2008). The Integration of Information Technology and Personnel Management in Colleges and Universities. Business Culture, No. 7, 162-163.

Ma, J. (2007). Primary Investigation on the Construction of Personnel Information Management System in Colleges and Universities. Science and Technology Information, No. 21, 339-341.

Wang, L. (2011). Discussion on the Application of Information Technology in Personnel Management System in Colleges and Universities. The Border Economy and Culture, No. 12, 167-168.

Yao, M. (2012). Analysis on the Construction of Personnel Management in Colleges and Universities. Higher Education Press, No. 2, 129-130.

Zhang, A.A. (2014). Primary Investigation on the Information Construction of Personnel Management in Colleges and Universities. Shaanxi Higher Education Social Science Journals, No. 8, 86-88. 